\title{
The expression level of CSDAP1 in lung cancer and its clinical significance
}

\author{
TONGBAI XU, DONGSHENG LI, YUAN HE, FULIANG ZHANG, MAN QIAO and YANHUA CHEN
}

Department of Respiratory Medicine, Tianjin Nankai Hospital, Tianjin 300100, P.R. China

Received September 14, 2017; Accepted July 11, 2018

DOI: $10.3892 / 01.2018 .9195$

\begin{abstract}
Expression level of messenger RNA (mRNA) of cold shock domain protein A intronless pseudogene (CSDAP1) in lung cancer tissues was studied. Fresh pathological specimens collected from 317 patients with primary lung cancer through surgical resection from January 2007 to January 2012 were selected. Reverse transcription-polymerase chain reaction (RT-PCR) and western blot analysis were used to detect the transcription and translation of CSDAP1 in lung cancer tissues and cancer-adjacent normal tissues, and the results were analyzed in combination with clinicopathological features and prognosis of lung cancer. Among 317 lung cancer specimens, 105 cases (33.1\%) had high expression of CSDAP1. Among 138 cases of pulmonary adenocarcinoma, 59 cases had high expression of CSDAP1, and the high expression rate was $42.8 \%$. Among 170 cases of lung squamous cell carcinoma, 46 cases had high expression of CSDAP1, and the high expression rate was $27.5 \%$ $(\mathrm{P}<0.05)$. Three cases of large cell carcinoma and 9 cases of small cell carcinoma had extremely low expression or had no expression of CSDAP1. Among the 127 lung cancer patients with regional lymph node metastasis, 53 cases $(41.7 \%)$ had high expression of CSDAP1, while among the 190 lung cancer patients without regional lymph node metastasis, 52 cases $(27.4 \%)$ had high expression of CSDAP1 $(\mathrm{P}<0.05)$. The results also revealed that the expression of CSDAP1 was also related to tumor-nodemetastasis (TNM) staging of lung cancer. One-year, three-year and five-year survival rates of lung cancer patients who had no expression of CSDAP1 were relatively high $(\mathrm{P}<0.05)$. The results suggested that CSDAP1 may play an important role in the occurrence, development and judgement of prognosis of lung cancer.
\end{abstract}

\section{Introduction}

Lung cancer is the main cause of cancer-related death worldwide. In China, approximately 2.5 million people die of this

Correspondence to: Dr Tongbai Xu, Department of Respiratory Medicine, Tianjin Nankai Hospital, 122 Sanwei Road, Tianjin 300100, P.R. China

E-mail: xcbqj2@163.com

Key words: CSDAP1, lung cancer, RT-PCR, western blot, clinical significance disease each year, and lung cancer is the first leading cause of cancer-related deaths in men and the third leading cause of death in women (1). Incidence of lung cancer in developing countries will continue to rise (1). Lung cancer at early stages has no obvious influence on patient life, and most patients were diagnosed at advanced stages, leading to poor treatment outcomes and prognosis. Even with proper chemotherapy, the 5-year survival rate is still unacceptably low. At present, genetargeted therapy provides a new approach for the treatment of lung cancer (2). EGFR-TKI resistance is main cause of poor survival of patients with lung cancer. Therefore, other genes related to lung tumors remains to be identified.

As a hot topic in recent years, pseudogenes have been found in more and more eukaryotes since the concept of pseudogene was introduced. Pseudogenes are a group of DNA sequences that have similar sequences with functional genes, but they lack protein-coding ability (3). However, it was reported that not all pseudogenes can be transcribed (4). A bioinformatics analysis carried out by Harrison et al (5) found that there are 233 transcribable pseudogenes in the human genome. CSDAP1 is one of the pseudogenes of CSDA. Reverse transcription-polymerase chain reaction (RT-PCR) and western blot analysis were used in this study to detect the expression levels of messenger RNA (mRNA) and protein of cold shock domain protein A intronless pseudogene (CSDAP1) in lung cancer tissues and cancer-adjacent normal tissues. Methyl thiazolyl tetrazolium (MTT) was used to detect the activity of lung cancer cells. This study was conducted to explore the significance of CSDAP1 in lung cancer.

\section{Materials and methods}

Clinical data. A total of 317 patients (age range 27-83 years; median 59 years) with primary lung cancer who received surgeries in Tianjin Nankai Hospital from January 2007 to January 2012 were selected. Lung cancer tissues and normal lung tissues more than $3 \mathrm{~cm}$ away from the cancer were collected for study. Complete clinical data were available for all the patients. None of the patients received chemotherapy, radiotherapy or other anti-tumor therapies prior to surgeries, and they were free from other malignant tumor diseases or severe renal and hepatic damage. Pathologic types and stages of the 317 patients with lung cancer were determined as per imaging, B ultrasound and post-operative pathological biopsy results. The patients included 219 males and 58 females, 
including 138 cases of pulmonary adenocarcinoma, 167 cases of lung squamous cell carcinoma, 3 cases of large cell carcinoma and 9 cases of small cell carcinoma. In total, 127 patients had lymph node metastasis, while 190 cases had no lymph node metastasis. According to tumor-nodemetastasis (TNM) pathological staging, 179 patients suffered from stage I-II lung cancer, and 138 patients suffered from stage III-IV lung cancer. According to histological grading, 147 patients suffered from moderately to highly differentiated lung cancer, and 170 patients suffered from poorly differentiated or undifferentiated lung cancer. Statistics of the follow-up visit was conducted on all the lung cancer patients up to January 2017, which showed that 23 patients withdrew from the follow-up visit. The rate of follow-up visit was $92.7 \%$. All the lung cancer patients underwent follow-up visits for 5 years.

This study was approved by the Ethics Committee of Tianjin Nankai Hospital (Tianjin, China), and all the patients signed informed consent. Pre-operative general data of the patients are given in Table I.

Cell lines and siRNA. Human alveolar basal epithelial cells (A549), human lung adenocarcinoma cell line (Calu-3), human embryonic fibroblasts (MRC-5), human small cell lung cancer cells (NCI-H446) and human lung cancer cells (PC-9) were purchased from American type Culture Collection (Manassas, VA). One siRNA was designed and chemically synthesized based on the sequence characteristics of CSDAP1.

$R N A$ isolation and reverse transcription-quantitative polymerase chain reaction ( $R T-q P C R)$. Lung cancer tissues and normal tissues more than $3 \mathrm{~cm}$ away from the cancer were taken from all the patients. TRIzol ${ }^{\mathrm{TM}}$ reagents (Invitrogen; Thermo Fisher Scientific, Inc., Waltham, MA, USA) were used to extract total RNA from the lung cancer tissues and normal lung tissues. CSDAP1-set small interfering RNA (siRNA) Lentivector kits (Nanjing EnoGene Biotech.Co.,Ltd.,Nanjing, China) were used to detect mRNA expression of CSDAP1 in lung cancer tissues and normal lung tissues by RT-PCR method. Primer sequences used were: CSDAP1 amplification (452 bp): 5'-TACGTCCAAGGTCGGGCAGGAAGA-3'; upstream: 5'-CACTGATAGGCAGTTCTC; downstream: 5'-GGTTCTCAGTTGGTGCTTC. Glyceraldehyde-3phosphate dehydrogenase (GAPDH) was taken as internal reference to detect mRNA expression level of CSDAP1 in the cells. All the selected mRNAs were pre-degenerated for $5 \mathrm{~min}$ at $95^{\circ} \mathrm{C}$, and $1 \mathrm{~min}$ at $94^{\circ} \mathrm{C}$ for 35 cycles. Then they were pre-degenerated for $1 \mathrm{~min}$ at $56^{\circ} \mathrm{C}, 2 \mathrm{~min}$ at $72^{\circ} \mathrm{C}$ and $10 \mathrm{~min}$ at $72^{\circ} \mathrm{C}$. The relative expression level of mRNA of CSDAP1 was expressed as $2^{-\Delta \Delta \mathrm{Cq}}\left(2^{-\Delta \Delta \mathrm{Cq}} \geq 2\right.$ was regarded as high expression) (6).

Analysis of protein expression of CSDAP1 by western blot analysis. The protein-containing cell debris was washed twice with phosphate buffer. Radio-immunoprecipitation assay (RIPA) lysis buffer (Beyotime Institute of Biotechnology, Shanghai, China) was added, and stored in a refrigerator at $-80^{\circ} \mathrm{C}$ for standby after centrifugation at $2,000 \mathrm{x}$ g for $5 \mathrm{~min}$ at $4^{\circ} \mathrm{C}$. Sodium sulfate-polyacrylamide $\left(\mathrm{Na}_{2} \mathrm{SO}_{4}-\mathrm{PAM}\right)$ was used to carry out protein gel electrophoresis, and the debris
Table I. Pre-operative general data of 317 lung cancer patients.

\begin{tabular}{lrc}
\hline Patient characteristics & $\mathrm{n}$ & $\%$ \\
\hline Sex & & \\
Male & 219 & 69.1 \\
Female & 98 & 30.9 \\
Age (years) & & \\
$\quad \leq 40$ & 49 & 15.5 \\
$40-60$ & 113 & 35.6 \\
$>60$ & 155 & 48.9 \\
Lymph node metastasis & & \\
Yes & 127 & 40.1 \\
No & 190 & 59.9 \\
Diameter of tumors & & \\
$\leq 3$ cm & 128 & 40.4 \\
$>3$ cm & 189 & 59.6 \\
Body mass index & & \\
Less than normal & 116 & 36.6 \\
Normal & 103 & 32.5 \\
Higher than normal & 98 & 30.9 \\
Smoking index (cigarette/year) & & 33.8 \\
No smoking & 98 & \\
$>400$ & 112 & 30.9 \\
$<400$ & & \\
\hline
\end{tabular}

Table II. Expression of CSDAP1 in lung cancer tissues and that in cancer-adjacent normal tissues.

\begin{tabular}{lccc}
\hline & \multicolumn{2}{c}{ CSDAP1 } & \\
\cline { 2 - 3 } Type of tissues & $\begin{array}{c}\text { High } \\
\text { expression }\end{array}$ & $\begin{array}{c}\text { Low } \\
\text { expression }\end{array}$ & P-value \\
\hline Lung cancer tissues & 105 & 212 & $<0.01$ \\
Cancer-adjacent tissues & 7 & 310 & \\
\hline
\end{tabular}

was transferred to nitrocellulose (NC) fibrous membrane. Then the membrane was blocked at room temperature for $1 \mathrm{~h}$ with 5\% skimmed milk. The membrane was incubated overnight with rabbit polyclonal HMGA2 antibody (dilution: 1/500; cat.no: ab52039), rabbit polyclonal Bcl-2 antibody (dilution, 1:500; cat. no.: ab59348), rabbit polyclonal E-cadherin antibody (dilution, 1:500; cat. no.: ab15148) and rabbit polyclonal $\beta$-actin antibody (dilution, 1:1,000; cat. no.: ab8227) at $4^{\circ} \mathrm{C}$, separately. The membrane was then incubated with secondary goat anti-rabbit (HRP) IgG antibody (dilution, 1:2,000; cat. no.: ab6721) at room temperature for $1 \mathrm{~h}$. All the antibodies were purchased from Abcam (Cambridge, MA, USA). Then chemiluminescence was performed using a luminometer (Hitachi, Tokyo, Japan).

Detection of in vitro proliferation of lung cancer cells with methyl thiazolyl tetrazolium (MTT) method. The accurately 
Table III. Correlation of CSDAP1 expression in lung cancer with clinicopathological features.

\begin{tabular}{|c|c|c|c|c|c|c|}
\hline \multirow[b]{2}{*}{ Parameters } & \multirow[b]{2}{*}{$\mathrm{n}$} & \multirow[b]{2}{*}{$\%$} & \multicolumn{2}{|c|}{ CSDAP1 } & \multirow[b]{2}{*}{$\chi^{2}$ value } & \multirow[b]{2}{*}{ P-value } \\
\hline & & & High expression & Low expression & & \\
\hline Sex & & & & & 0.09 & 0.764 \\
\hline Male & 219 & 38.4 & 84 & 135 & & \\
\hline Female & 58 & 36.2 & 21 & 37 & & \\
\hline Age (years) & & & & & 0.461 & 0.794 \\
\hline$\leq 40$ & 49 & 36.7 & 18 & 31 & & \\
\hline $40-60$ & 113 & 33.6 & 38 & 75 & & \\
\hline$>60$ & 155 & 31.6 & 49 & 106 & & \\
\hline Diameter of tumors & & & & & 0.683 & 0.409 \\
\hline$\leq 3 \mathrm{~cm}$ & 128 & 30.5 & 39 & 89 & & \\
\hline$>3 \mathrm{~cm}$ & 189 & 34.9 & 66 & 123 & & \\
\hline Differentiation degree & & & & & 3.387 & 0.066 \\
\hline Middle and high differentiation & 147 & 27.9 & 41 & 106 & & \\
\hline Low (non) differentiation & 170 & 37.6 & 64 & 106 & & \\
\hline Types of tissues & & & & & 7.742 & 0.005 \\
\hline Pulmonary adenocarcinoma & 138 & 42.8 & 59 & 79 & & \\
\hline Lung squamous cell carcinoma & 167 & 27.5 & 46 & $121^{\mathrm{a}}$ & & \\
\hline Lymph node metastasis & & & & & 7.09 & 0.008 \\
\hline Yes & 127 & 41.7 & 53 & 74 & & \\
\hline No & 190 & 27.4 & 52 & 138 & & \\
\hline Clinical staging & & & & & 11.83 & 0.001 \\
\hline I-II & 179 & 25.1 & 45 & 134 & & \\
\hline III-IV & 138 & 43.5 & 60 & 78 & & \\
\hline
\end{tabular}

${ }^{a}$ Compared with the High expression group. $\mathrm{P}<0.05$.

counted cells were inoculated in 96-well plates in a concentration of $1.5 \times 10^{3}$ cells/well. At $24 \mathrm{~h}$ later, the tumor cells were taken out for experimental culture when they were in logarithmic growth phase. After that, new culture medium was added to carry out culturing for $48 \mathrm{~h}$; then the detection of cell activity was conducted. MTT was added to each well, and the culture dish was placed in a thermostatic incubator to incubate the cells for another $3 \mathrm{~h}$. The supernatant was removed by centrifugation at $2,000 \mathrm{x}$ for $5 \mathrm{~min}$ at $4^{\circ} \mathrm{C}$, and dimethyl sulfoxide was added. Incubation was conducted again for $15 \mathrm{~min}$ at room temperature. The absorbance was measured at the wavelength of $570 \mathrm{~nm}$.

Statistical analysis. Statistical Product and Service Solutions (SPSS) 22.0 (IBM Corp., Armonk, NY, USA) was used for statistical analysis. ANOVA test was used for comparison of multiple groups and the comparison of multiple groups was carried out using SNK test. The data were analyzed, and the measurement data were expressed as (mean $\pm \mathrm{SD}$ ). The $\chi^{2}$ test was performed for comparison of CSDAP1 expression levels and clinical factors. The post-operative survival rate was calculated as per Kaplan-Meier survival curve. Significance test was conducted using the log-rank test for univariate analysis. Statistically significant variables $(\mathrm{P}<0.01)$ in the univariate analysis were included in the Cox model to carry

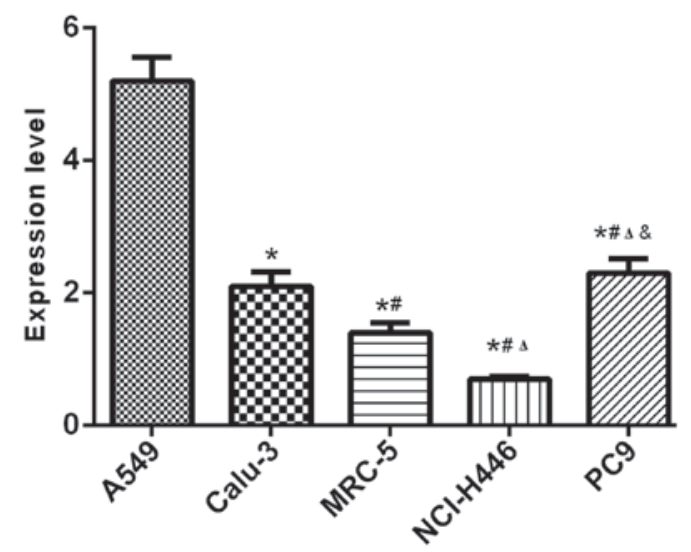

Figure 1. Detection of CSDAP1 expressions in lung cancer cells with RT-PCR Comparison among all groups showed a statistical difference $(F=62.457$, $\mathrm{P}=0.001)$. Comparisons between 2 groups showed that the highest expression level of CSDAP1 mRNA in A549 cells was significantly higher than the expression level of CSDAP1 mRNA in other groups of cells (Calu-3t=7.519, Calu-3 P=0.017; MRC-5t=9.979, MRC-5 P=0.010; NCI-H446t=12.665, NCI-H446 $\mathrm{P}=0.006$; $\mathrm{PC} 9 \mathrm{t}=7.034$, $\mathrm{PC} 9 \mathrm{P}=0.020)$. * $\mathrm{P}<0.05$ compared with A549. ${ }^{~} \mathrm{P}<0.05$ compared with CP-9. ${ }^{\Delta} \mathrm{P}<0.05$ compared with MRC-5; ${ }^{\&}$ compared with NCI-H446

out multivariate analysis. $\mathrm{P}<0.05$ indicated that the difference was statistically significant. 
Table IV. Multivariate analysis of prognosis in patients with lung cancer.

\begin{tabular}{lccrrrr}
\hline Factors & $\begin{array}{c}\text { Estimated } \\
\text { value }\end{array}$ & $\begin{array}{c}\text { Standard } \\
\text { error }\end{array}$ & $\begin{array}{c}\text { Wald } \\
\text { value }\end{array}$ & P-value & $\begin{array}{c}\text { OR } \\
\text { value }\end{array}$ & $\begin{array}{c}95 \% \text { confidence } \\
\text { interval (CI) }\end{array}$ \\
\hline Expression of CSDAP1 & -1.503 & 0.278 & 39.523 & $<0.001$ & 3.702 & $0.121-0.630$ \\
TNM staging & 2.823 & 1.124 & 5.021 & 0.007 & 1.963 & $0.623-2.477$ \\
Lymph node metastasis & -2.017 & 0.896 & 7.431 & 0.001 & 2.305 & $0.503-2.135$ \\
\hline
\end{tabular}

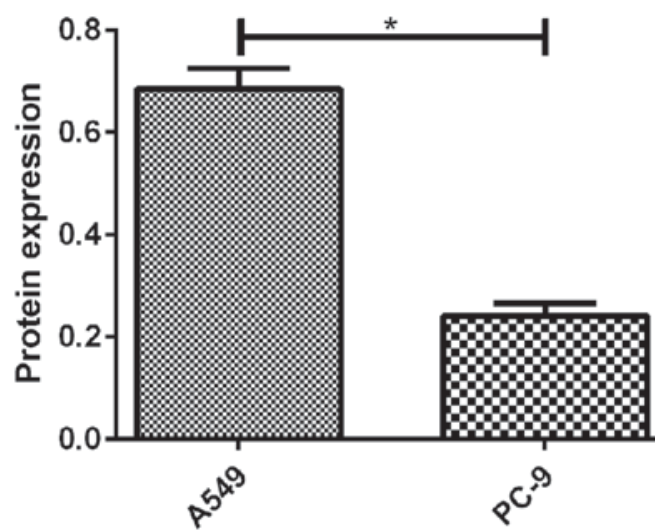

Figure 2. Detection of CSDA in lung cancer A549 and NCI-H446 cells by western blot analysis. Expression of CSDA in A549 and PC-9 was detected by western blot analysis and results showed that there was a significant difference in the expression of CSDA protein between the two groups of cells $(\mathrm{t}=9.517, \mathrm{P}=0.001) .{ }^{*} \mathrm{P}<0.05$.

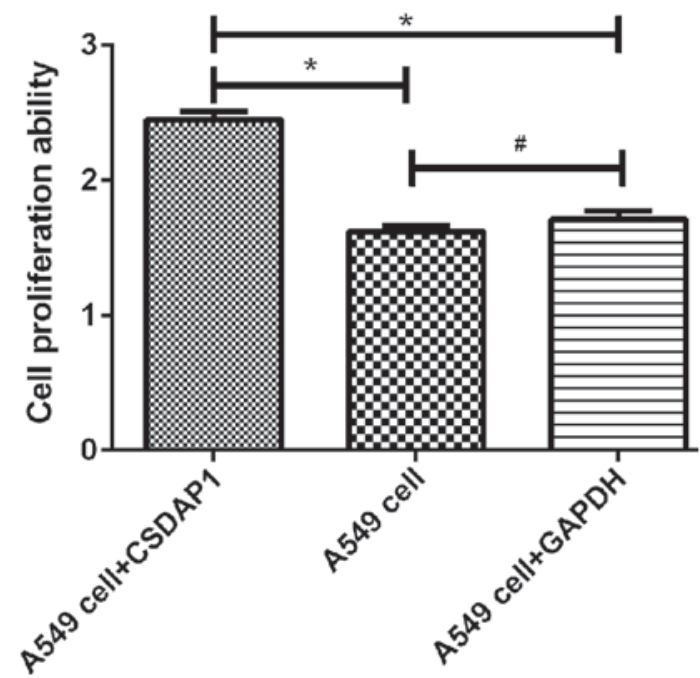

Figure 3. Comparison of activity of lung cancer A549 cells detected with MTT method. The results of MTT assay showed that viability of A549 cells treated with CSDAP1 was significantly higher than that of untreated A549 cells and A549 cells treated with GAPDH (untreated A549t=11.226, untreated A549 P=0.001; A549t treated with GAPDH=8.622, A549P treated with GAPDH=0.001), and there was no statistical difference in viability of untreated A549 cells and GAPDH-treated A549 cells ( $\mathrm{t}=1.146, \mathrm{P}=0.615)$. ${ }^{*} \mathrm{P}<0.05 ;{ }^{*} \mathrm{P}>0.05$.

\section{Results}

Expression of CSDAPl in lung cancer tissues and that in normal tissues. The expression of CSDAP1 in lung cancer

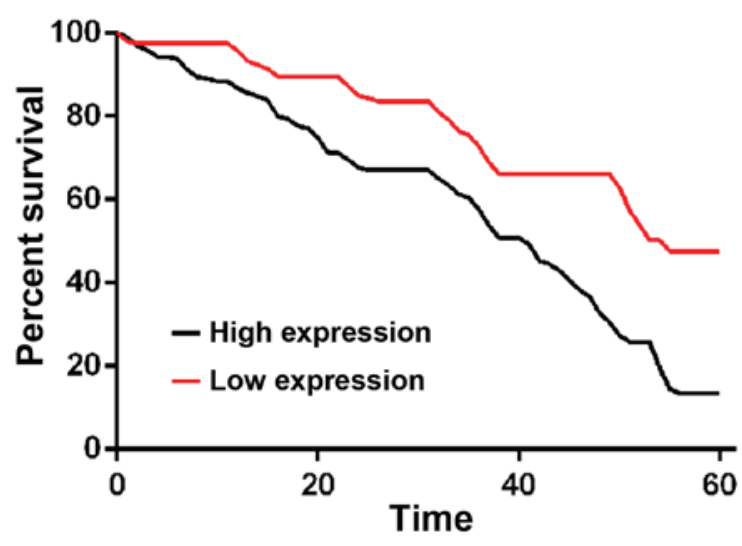

Figure 4. Survival curve of patients with high expression of CSDAP1 and those with low expression of CSDAP1. Patients were divided into high expression group and low expression group according to the median expression level of CSDAP1 mRNA. Survival rate of patients with low expression was significantly higher than that of patients with high expression $(\mathrm{P}<0.001)$.

tissues was obviously higher than that in cancer-adjacent normal tissues. The difference had statistical significance $(\mathrm{P}<0.01)$ (Table II).

In this study, the high expression of CSDAP1 had no obvious differences in the comparison of age and sex of lung cancer patients as well as the diameter and differentiation degree of the cancer. The difference had no statistical significance $(\mathrm{P}>0.05)$. The high expression rate of CSDAP1 in the cancer tissues of 138 patients with pulmonary adenocarcinoma was $42.8 \%$, while that in 167 patients with lung squamous cell carcinoma was $27.5 \%$. The difference between them was significant $(\mathrm{P}=0.05)$. The high expression rate of CSDAP1 in the cancer tissues of 127 lung cancer patients with lymph node metastasis was $41.7 \%$, while that in the cancer tissues of 190 lung cancer patients without lymph node metastasis was $27.4 \%$. The difference between them was significant $(\mathrm{P}<0.008)$. The high expression rate of CSDAP1 in patients with stage I-II lung cancer was $25.1 \%$, which was less than that in patients with stage III-IV lung cancer $(43.5 \%)$ $\mathrm{P}=0.001$ (Table III).

Results of RT-qPCR and western blot analysis showed that the expression levels of CSDAP1 in lung cancer cells such as human alveolar basal epithelial cells (A549), human lung adenocarcinoma cell line (Calu-3), human embryonic fibroblasts (MRC-5), human small cell lung cancer cells (NCI-H446) and human lung cancer cells (PC-9) were different in transcription and translation, among which, A549 and PC-9 had relatively high expression levels (Figs. 1 and. 2). 
Detection of activity of A549 in lung cancer with MTT method. The activity of A594 containing CSDAP1 was (2.45 \pm 0.1 , which was increased significantly compared with that of the unprocessed A549 (1.62 \pm 0.08$)$ and that of A549 containing GAPDH $(1.71 \pm 0.11)$. The differences had statistical significance $(\mathrm{P}<0.05)$ (Fig. 3).

Parameters showing $\mathrm{P}<0.1$ in univariate analysis were included in Cox proportional hazard regression model. The results showed that CSDAP1, lymph node metastasis and clinical staging were independent risk factors for prognosis of lung cancer $(\mathrm{P}<0.05)$ (Table IV).

The comparison of 1-, 3- and 5-year survival rates between patents with a high expression of CSDAP1 and those with a low expression of CSDAP1 in lung cancer tissues showed that 1- , 3- and 5-year survival rates of patients with high expression of CSDAP1 were lower than those of patients with low expression of CSDAP1 in lung cancer tissues (Fig. 4).

\section{Discussion}

Drug resistance in lung cancer is closely related to therapeutic effects. Although there are many new treatments such as biotherapy and targeted therapy (7), and the level of treatment of lung cancer continues to increase, the survival rate of lung cancer patients remains unsatisfactory. Moreover, how we can effectively predict the occurrence and development of lung cancer, and how to choose treatment programs constitute challenges in the treatment of lung cancer at present. Therefore, it is particularly critical to identify more effective genes against tumor cells.

CSDA is widely found in animals, plants and microorganisms. It is a member of the cold shock domain protein gene (8-10), which can express lung, ovary, prostate, colorectum, in various tissues. Its expression is realized through response to cold shock (11), especially in the response to cold-shock stimulation. Currently, cold shock domain proteins have been used as tumor markers.

Current findings showed that the expression of CSDAP1 in normal tissues is very small, while that in various malignant tumors is increased. For example, CSDAP1 is closely related to tumors such as breast, ovarian, prostate and colon cancer (12), and it can be used as risk factors for prognosis in these tumors. At present, the relationship between the expression of CSDAP1 in lung cancer and the prognosis is not confirmed yet. In this study, an analysis on the expression level of CSDAP1 and different pathologic features of lung cancer patients was conducted. There are few studies on the relationship between CSDAP1 and clinicopathological features of lung cancer. In this study, the correlation of CSDAP1 with lung cancer is analyzed. The experiment using RT-qPCR method and western blot analysis showed that the expression of CSDAP1 in lung cancer tissues was obviously higher than that in cancer-adjacent normal tissues. The difference had statistical significance. Diamond et al (13) suggested that the cold shock domain protein is transferred to the nucleus through coordinating the expression of P53 and is involved in the occurrence and drug resistance of bladder cancer. A study conducted by Tang et al (14) showed that CSDAP1 can be used as the function of growth stimulus in tumor cells, and indicated that the overexpression of CSDAP1 in colon cancer and prostate cancer and the downregulation of mRNA can significantly reduce the survival of tumor cells and enhance the response of prostate cancer cells to chemotherapy. The aforementioned results indicated that the high expression of CSDAP1 may be closely related to the occurrence and development of tumors such as lung cancer $(15,16)$. The mechanism of CSDAP1 with diseases such as tumors needs to be further verified in future studies.

In this study, it was found that the median survival time of lung cancer patients with high expression of CSDAP1 was significantly shorter than that of lung cancer patients with low expression of CSDAP1, and that the survival prognosis of lung cancer patients with high expression of CSDAP1 was significantly lower than that of lung cancer patients with low expression of CSDAP1, which confirmed that the expression of CSDAP1 may be closely related to the prognosis of lung cancer. Multivariate analysis revealed that CSDAP1, lymph node metastasis and clinical staging could be used as independent risk factors of prognosis in lung cancer $(17,18)$, which is basically consistent with the conclusion drawn in large clinical trials conducted by Zimmermann et al (19). The aforementioned results suggested that patients with high expression of CSDAP1 may have relatively poor prognosis. Further studies on the value of CSDAP1 in moleculartargeted therapy $(20,21)$ may be the direction of current studies.

This experiment has shortcomings, for example, it is a scientific study conducted in only one medical center, the sample size is insufficient and there are geographical differences in the samples used for the experiment. We studied this pseudogenic gene for the first time, and then we found that there was no related literature to describe it before, and most of them were screened by gene sequencing and GO enrichment. The functional mechanism was not well studied. If a large sample size with patients from different regions and ethnicities is available for future investigations, the significance of this experiment may be confirmed. In addition, future studies are to focus on the functional mechanism.

In conclusion, the expression level of CSDAP1 can be used as an important factor for predicting prognosis in lung cancer patients, especially those in the early stage. However, as the expression of CSDAP1 in normal tissues is too low or absent, its clinical effects can be proven further by combining with the expression level of CSDAP1 protein. In this study, CSDAP1 may play an important role in the occurrence, development and the judgement of prognosis of lung cancer.

\section{Acknowledgements}

Not applicable.

\section{Funding}

No funding was received.

\section{Availability of data and materials}

The datasets used and/or analyzed during the present study are available from the corresponding author on reasonable request. 


\section{Authors' contributions}

TX and DL conceived and designed the study. TX, YH and FZ were responsible for the collection and analysis of data. TX, MQ and YC interpreted the data and drafted the manuscript. DL and YH revised the manuscript critically for important intellectual content. All authors have read and approved the final manuscript.

\section{Ethics approval and consent to participate}

The study was approved by the Ethics Committee of Tianjin Nankai Hospital (Tianjin, China). Signed informed consent was obtained from the patients or the guardians.

\section{Patient consent for publication}

Not applicable.

\section{Competing interests}

The authors declare that they have no competing interests.

\section{References}

1. Tang H, Wang S, Xiao G, Schiller J, Papadimitrakopoulou V, Minna J, Wistuba II and Xie Y: Comprehensive evaluation of published gene expression prognostic signatures for biomarkerbased lung cancer clinical studies. Ann Oncol 28: 733-740, 2017.

2. Xu C, Xie S, Song C, Huang L and Jiang Z: Lin28 mediates cancer chemotherapy resistance via regulation of miRNA signaling. Hepatogastroenterology 61: 1138-1141, 2014.

3. De Martino M, Forzati F, Arra C, Fusco A and Esposito F: HMGA1-pseudogenes and cancer. Oncotarget 7: 28724-28735, 2016.

4. Lister N, Shevchenko G, Walshe JL, Groen J, Johnsson P, Vidarsdóttir L, Grander D, Ataide SF and Morris KV: The molecular dynamics of long noncoding RNA control of transcription in PTEN and its pseudogene. Proc Natl Acad Sci USA 114: 9942-9947, 2017.

5. Harrison PM, Zheng D, Zhang Z, Carriero N and Gerstein M: Transcribed processed pseudogenes in the human genome: An intermediate form of expressed retrosequence lacking proteincoding ability. Nucleic Acids Res 33: 2374-2383, 2005.

6. Livak KJ and Schmittgen TD: Analysis of relative gene expression data using real-time quantitative PCR and the 2(-Delta Delta C(T)) Method. METHODS 25: 402-408, 2001.

7. Zhu YJ, Zhang HB, Liu YH, Zhu YZ, Chen J, Li Y, Bai JP, Liu LR, Qu YC, Qu X, et al: Association of mutant EGFR L858R and exon 19 concentration in circulating cell-free DNA using droplet digital PCR with response to EGFR-TKIs in NSCLC. Oncol Lett 14: 2573-2579, 2017.
8. Wang X, Che H, Zhang W, Wang J, Ke T, Cao R, Meng S, Li D, Weiming $\mathrm{O}$, Chen J, et al: Effects of mild chronic intermittent cold exposure on rat organs. Int J Biol Sci 11: 1171-1180, 2015.

9. Dal Piaz F, Terracciano S, De Tommasi N and Braca A: Hsp90 activity modulation by plant secondary metabolites. Planta Med 81: 1223-1239, 2015.

10. Kanshin E, Kubiniok P, Thattikota Y,D'Amours D and Thibault P: Phosphoproteome dynamics of Saccharomyces cerevisiae under heat shock and cold stress. Mol Syst Biol 11: 813, 2015.

11. Tanabe Y, Nagatoishi S and Tsumoto K: Thermodynamic characterization of the interaction between the human Y-box binding protein YB-1 and nucleic acids. Mol Biosyst 11: 2441-2448, 2015.

12. Cai CJ, Ye SJ, Zhu W, Sun LY, Wan HS, Feng ZH, Ma L and Li L: Study on invasion and metastasis-associated genes of lung cancer related with NM23-H1 gene. Sichuan Da Xue Xue Bao Yi Xue Ban 41: 941-945, 2010 (In Chinese).

13. Diamond P, Shannon MF, Vadas MA and Coles LS: Cold shock domain factors activate the granulocyte-macrophage colonystimulating factor promoter in stimulated Jurkat T cells. J Biol Chem 276: 7943-7951, 2001.

14. Tang C, Wang Y, Lan D, Feng X, Zhu X, Nie P and Yue H: Analysis of gene expression profiles reveals the regulatory network of cold-inducible RNA-binding protein mediating the growth of BHK-21 cells. Cell Biol Int 39: 678-689, 2015.

15. Kalamida D, Karagounis IV, Mitrakas A, Kalamida S, Giatromanolaki A and Koukourakis MI: Fever-range hyperthermia vs. hypothermia effect on cancer cell viability, proliferation and HSP90 expression. PLoS One 10: e0116021, 2015.

16. Hung MS, Lin YC, Mao JH, Kim IJ, Xu Z, Yang CT, Jablons DM and You L: Functional polymorphism of the CK2alpha intronless gene plays oncogenic roles in lung cancer. PLoS One 5: e11418, 2010.

17. Chen SJ, Lin PW, Lin HP, Huang SS, Lai FJ, Sheu HM, Hsu LJ and Chang NS: UV irradiation/cold shock-mediated apoptosis is switched to bubbling cell death at low temperatures. Oncotarget 6 : 8007-8018, 2015.

18. Yamashita T, Higashi M, Momose S, Morozumi M and Tamaru JI: Nuclear expression of Y box binding-1 is important for resistance to chemotherapy including gemcitabine in TP53-mutated bladder cancer. Int J Oncol 51: 579-586, 2017.

19. Zimmermann M, Traxler D, Simader E, Bekos C, Dieplinger B, Lainscak M, Ankersmit HJ and Mueller T: In vitro stability of heat shock protein 27 in serum and plasma under different pre-analytical conditions: Implications for large-scale clinical studies. Ann Lab Med 36: 353-357, 2016.

20. Liu Y, Hu W, Murakawa Y, Yin J, Wang G, Landthaler M and Yan J: Cold-induced RNA-binding proteins regulate circadian gene expression by controlling alternative polyadenylation. Sci Rep 3: 2054, 2013.

21. Yu B, Wang J, He C, Wang W, Tang J, Zheng R, Zhou C, Zhang H, Fu Z, Li Q, et al: Cytokine-induced killer cell therapy for modulating regulatory $\mathrm{T}$ cells in patients with non-small cell lung cancer. Exp Ther Med 14: 831-840, 2017. 